\title{
Review
}

\section{Insulin-induced vasodilatation: physiology or pharmacology?}

\section{H. Yki-Järvinen, T. Utriainen}

University of Helsinki, Department of Medicine, Division of Endocrinology and Diabetology, Helsinki, Finland

Keywords Muscle, glucose, diabetes mellitus, hypertension, obesity, blood vessels, endothelium, atherosclerosis.

Ever since the pioneering studies performed by Andres, Rabinowitz and Zierler 40 years ago [1-4], investigators interested in insulin action considered insulin resistance in obesity [3], hypertension [5], insulin-dependent (IDDM) [6] and non-insulin-dependent diabetes mellitus (NIDDM) [7] to be primarily a problem of glucose utilization in peripheral tissues, which was independent of glucose delivery. However, a series of studies published since 1990, notably by Alain Baron and his associates, demonstrated that under certain conditions insulin increased leg blood flow [8], and that defects in this action of insulin were likely to contribute significantly to insulin resistance of glucose uptake caused by obesity [8], hypertension [9], IDDM [10] and NIDDM [11]. These latter findings contradicted the vast majority of earlier data and created a controversy regarding the role, or lack thereof, of defects in insulin stimulated blood flow in the pathogenesis of insulin resistance of glucose uptake. It is the purpose of the ensuing review to try to discuss the reasons for the discrepant findings. We will first review a series of studies performed in our own laboratory, which were designed to resolve the "flow controversy". These studies examined whether the blood flow response to insulin is influ-

Corresponding author: H. Yki-Järvinen, M.D., University of Helsinki, Department of Medicine, Division of Endocrinology and Diabetology, Haartmaninkatu 4, FIN-00290 Helsinki, Finland

Abbreviations: IDDM, Insulin-dependent diabetes mellitus; NIDDM, non-insulin-dependent diabetes mellitus; PET, positron emission tomography; $\mathrm{NO}$, nitric oxide; ${ }^{18} \mathrm{FDG},\left[{ }^{18} \mathrm{~F}\right]$ fluoro-deoxy-glucose; MAP, mitogen activated protein. enced by: i) the method used to quantitate blood flow; ii) the anatomical location of the flow measurement; iii) dose and duration of the insulin exposure; iv) individual factors such as limb muscularity, physical fitness and endothelial function, defined as the ability to vasodilate in response to nitric oxide (NO) synthesis-dependent vasodilatators. We will try to establish whether this physiological knowledge helps to explain the discrepancies observed in the studies performed in various insulin resistant conditions. We will then review the studies directly testing the hypothesis that an increase in blood flow enhances glucose uptake, and discuss the possibility that various vasoactive agents may change total flow similarly but have distinct effects on flow distribution. Finally, we will review studies relating insulin's vascular effects to endothelial function, which have opened up an entirely new perspective for understanding how insulin resistance might predispose to vascular disease.

\section{Determinants of insulin-induced vasodilatation}

Methodological aspects. Increases in blood flow by insulin have been reported under intravenously maintained normoglycaemic hyperinsulinaemic conditions using methods such as thermodilution $[8,12]$, dye dilution [13], venous occlusion plethysmography [14-16] and positron emission tomography (PET) combined with $\left[{ }^{15} \mathrm{H}_{2} \mathrm{O}\right]$ [17]. Doppler ultrasound appears to be clearly less sensitive in detecting changes in flow. In our hands, $6 \mathrm{~h}$ of supraphysiological hyperinsulinaemia increased blood flow on average by $113 \%$ when measured by venous occlusion plethysmography but only by $27 \%$ when measured with Doppler ultrasound. The latter change was due to a $10 \%$ increase in systolic peak flow velocity and an $18 \%$ increase in heart rate. The insensitivity of the Doppler ultrasound technique may explain why $\mathrm{Bu}-$ 


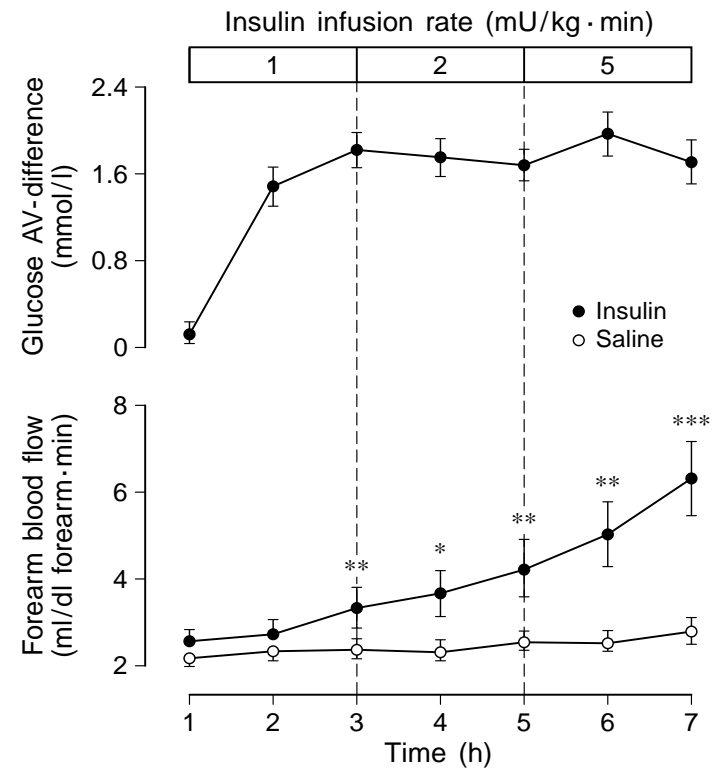

Fig. 1. Glucose arteriovenous difference (glucose extraction) and forearm blood flow plotted as a function of time during three sequential intravenous insulin infusions (-O) $(2 \mathrm{~h}$ each, serum insulin 61, 139 and $462 \mathrm{mU} / \mathrm{l})$. Open circles (-○-) denote flow during a saline control study. Adapted with permission from reference [19]. ${ }^{*} p<0.05 ;{ }^{* *} p<0.01 ;{ }^{* * *} p<0.001$ for flow vs $0-1 \mathrm{~h}$ (basal)

chanan et al. [18] failed to detect any increase in blood flow after $4 \mathrm{~h}$ of maximal hyperinsulinaemia (serum insulin $\sim 5000 \mathrm{mU} / \mathrm{l}$ ) in normal subjects. Flow has also failed to increase by insulin in many studies, regardless of the technique used (vide infra). These data imply that factors other than the method used to measure blood flow, with the exception of the Doppler ultrasound technique, are unlikely to explain the variable results.

Dose and duration of insulin exposure, site of insulin administration. In normal subjects, infusion of a fixed physiological dose of insulin $(1 \mathrm{mU} / \mathrm{kg} \cdot \mathrm{min})$, increases the glucose arteriovenous difference (glucose extraction) more rapidly than it increases blood flow across both leg [8] and the forearm [19] tissues. When measured across forearm tissues, an intravenous infusion of insulin $(1 \mathrm{mU} / \mathrm{kg} \cdot \mathrm{min})$ increases glucose extraction over 10 -fold ( $>1000 \%$ ) in $60 \mathrm{~min}$ in normal subjects [19]. Within this time period, there is no change in blood flow (Fig. 1). When the insulin infusion is continued, blood flow increases continuously, while glucose extraction plateaus (Fig.1). A similar pattern was observed by Laakso et al. [8] across the leg, in which glucose extraction also increased over 10 -fold $(>1000 \%)$ during the first hour of insulin infusion, and in which leg blood flow increased continuously. These data suggest that the ability of insulin to increase blood flow is critically dependent upon the duration of insulin exposure.

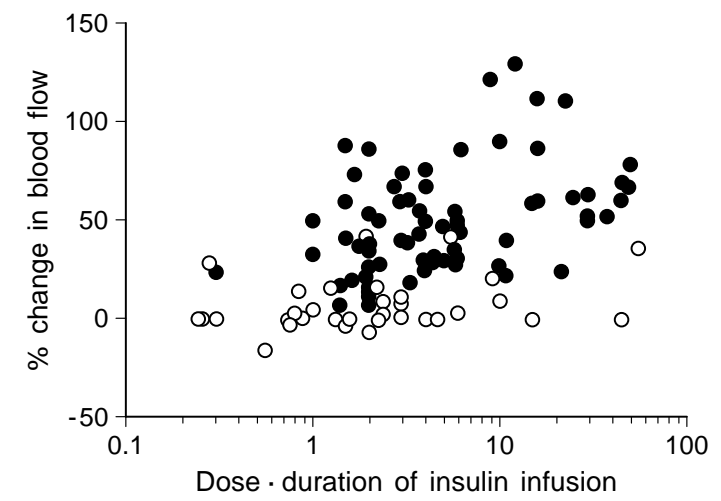

Fig. 2. Summary of studies $(n=75)$ examining the effect of intravenous insulin infusions on forearm or leg blood flow under normoglycaemic conditions in normal subjects. Individual studies in which the flow increased significantly $(\mathbf{O})$; studies in which the change in flow was not significant $(\bigcirc)$. A list of studies identifying each point can be obtained from the authors. An insulin exposure index was calculated by multiplying the dose of insulin ( $\mathrm{mU} / \mathrm{kg}$ body weight $\cdot \mathrm{min}$ ) by the duration of the insulin infusion (h), and plotted against the percent change in blood flow (usually measured during the last hour of the insulin infusion). The insulin exposure index was significantly correlated $(r=0.50, p<0.0001)$ with the percent change in blood flow, when all studies were pooled

The dose of insulin also appears to contribute to the blood flow response, but appears less important than time. Yki-Järvinen et al. [20] and Bonadonna et al. [13] measured forearm glucose uptake on separate days using different doses of insulin. At the highest concentrations of insulin (1600-1800 mU/l), blood flow increased by $25 \%$ during $130 \mathrm{~min}$ in the study by Bonadonna et al. [13] and by $15 \%$ during $120 \mathrm{~min}$ in the study of Yki-Järvinen et al. [20]. These increases in blood flow were again trivial compared to the increase in forearm glucose uptake, which increased more than 10-fold in both studies [13, 20].

To examine, based on the numerous studies available in the literature, whether the dose of insulin or the duration of the insulin infusion explains any of the contradictory findings regarding the effect of insulin on blood flow under normoglycaemic hyperinsulinaemic conditions, we plotted the percent increase in flow against an insulin exposure index, which was defined as the product of the insulin dose (in $\mathrm{mU} / \mathrm{kg} \cdot \mathrm{min}$ ) times the duration of the infusion (h). A significant correlation was observed both in studies where intravenous (Fig. 2, $n=75$ studies) and local (Fig. 3, $n=23$ studies) intraarterial insulin infusions were used, between the insulin exposure index and the percent change in blood flow. While this cross-sectional analysis demonstrates that either the duration of the insulin infusion or the insulin dose explains part of the variation between the various studies, additional factors are likely to contribute. For example, even the mean flow responses to a 2 -h infusion of insulin (insulin infusion rate $1 \mathrm{mU} / \mathrm{kg} \cdot \mathrm{min}$ ) have 


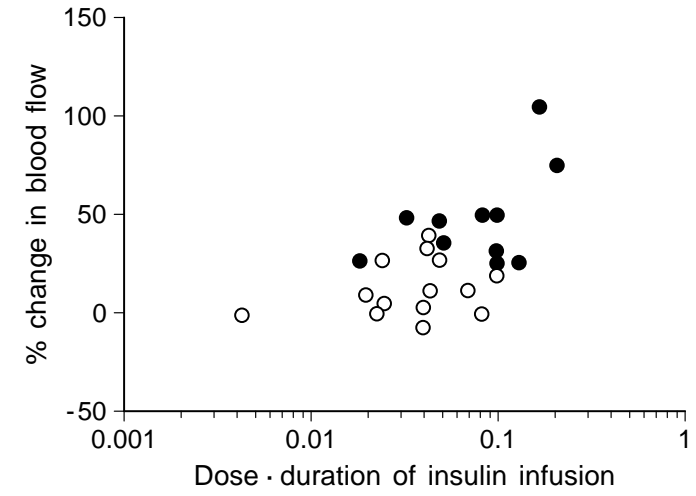

Fig.3. Summary of studies $(n=23)$ examining the effect of local intra-arterial insulin infusions on either forearm or leg blood flow under normoglycaemic conditions in normal subjects ( significant increase in flow, $\bigcirc$ no significant change in flow). A list of studies identifying each point can be obtained from the authors. An insulin exposure index was calculated by multiplying the dose of insulin ( $\mathrm{mU} / \mathrm{kg}$ forearm $\cdot \mathrm{min}$ ) by the duration of the insulin infusion ( $\mathrm{h}$ ), and plotted against the percent change in blood flow (usually measured during the last hour of the insulin infusion). The shaded $(O)$ and open $(\bigcirc)$ circles denote the individual studies where blood flow changed significantly and where it remained unchanged. The insulin exposure index was significantly correlated $(r=0.62, p<0.0001)$ with the percent change in blood flow when all studies were pooled

varied considerably from study to study and ranged from -1 to $87 \%$ (Fig. 2).

Flow response to insulin in forearm and leg tissues. Histological analysis of different human muscles has revealed that the proportions of slow-twitch, insulinsensitive (type I) and fast-twitch, less insulin-sensitive (type IIa and IIb) muscle fibres are remarkably similar in vastus lateralis, upper arm muscles such as the biceps and triceps brachii muscles and forearm muscles such as the brachioradialis, extensor and flexor digitorum muscles [21, 22]. Measurement of insulinstimulated glucose uptake rates using PET and $\left[{ }^{18} \mathrm{~F}\right]$ fluoro-deoxy-glucose $\left({ }^{18} \mathrm{FDG}\right)$ in the same subjects have shown similar rates of glucose uptake in arm and leg muscles in normal subjects as well as competitive runners [23]. Direct comparison of blood flow responses in the same subjects in cross-sections of the most muscular portions of the forearm and the calf demonstrated similar increases in blood flow in both regions (Fig.4) [19]. Finally, analysis of the studies shown in Figure 2 after subdivision according to the site of the blood flow measurement, is consistent with the conclusion that the relative and absolute blood flow responses are comparable in forearm and leg tissues (data not shown).

Individual factors. Direct measurements of blood flow in skeletal muscle using PET combined with $\left[{ }^{15} \mathrm{O}\right] \mathrm{H}_{2} \mathrm{O}$ have demonstrated that variation in basal

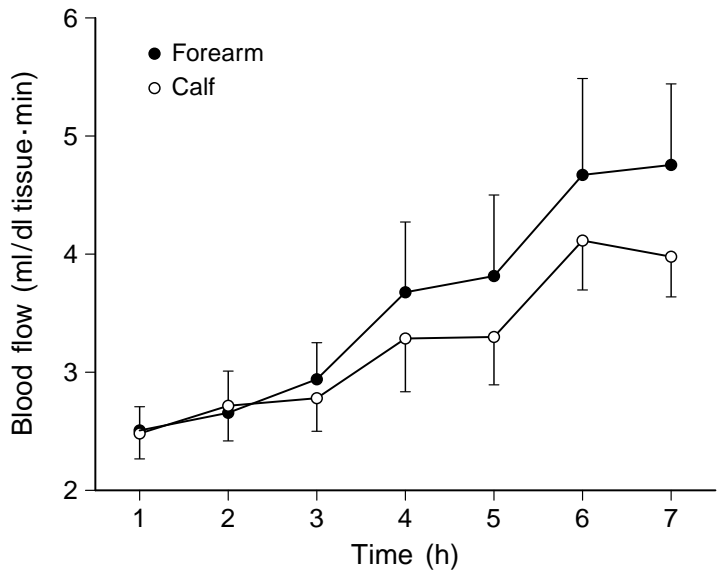

Fig. 4. Direct comparison of blood flow responses to insulin under normoglycaemic conditions in the same subjects in the forearm and the calf, using venous occlusion plethysmography to record blood flow. The experimental conditions were as described in the legend to Figure 1. From reference [19] with permission. The forearm and calf blood flow responses to insulin were not significantly different at any time point

flow between individuals can be attributed to variation in blood flow in skeletal muscle [24], and that skeletal muscle is the quantitatively predominant location for insulin stimulation of blood flow. Interindividual variation in limb muscularity could therefore influence the ability of insulin to stimulate blood flow. This is true at least in the forearm, in which muscle content varies almost fourfold (from 24 to $81 \%$ in [19]) even among healthy non-obese untrained men and women. In the latter study, a maximal insulin concentration increased blood flow, measured with venous occlusion plethysmography, almost fourfold more in individuals with the most muscular forearms than in those with the least muscular forearms (Fig.5). Forearm muscularity is closely correlated with physical fitness, as judged from maximal aerobic power $\left(\mathrm{VO}_{2} \mathrm{max}\right)$ [25]. Variation in skeletal muscle capillarization, measured from the ratio of capillaries to muscle fibres, is yet another parameter which correlates with the ability of insulin to stimulate blood flow [26]. Since control of capillary perfusion resides in terminal arterioles and proximal arteriolar segments [27], it is unlikely that vascular resistance attributable to capillaries explains the association between insulin-stimulated blood flow and the capillaries per fibre ratio. Although it is difficult, if not physiologically impossible to distinguish between the relative importance of closely related phenomena such as limb muscularity, physical fitness and the capillaries per fibre ratio, it is clear that these factors do play a role in modulating the blood flow response to insulin. These parameters could explain some of the variation, not attributable to the experimental conditions, in the flow response to insulin in the studies summarized in Figures 2 and 3. 


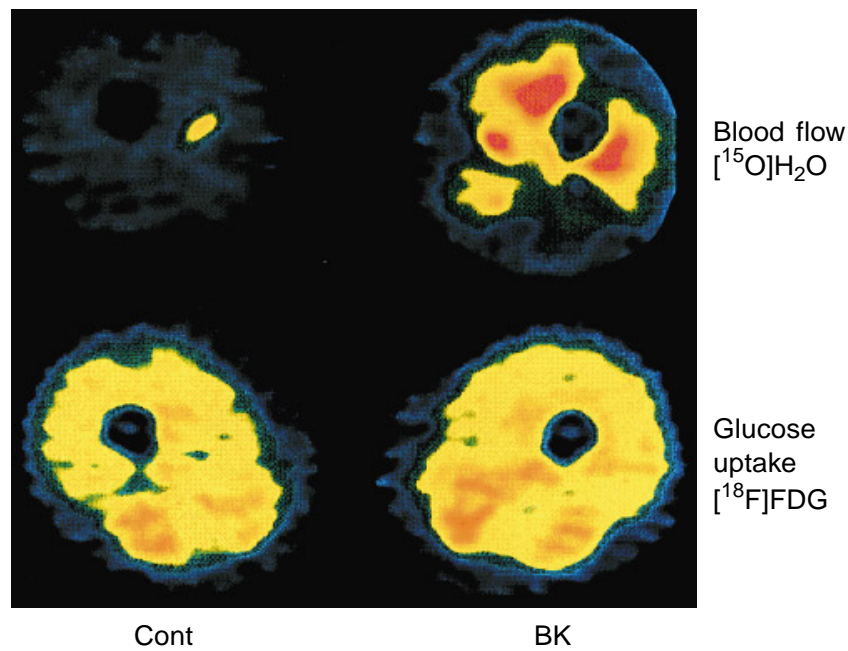

Fig.5. Cross-sectional images of blood flow in the femoral region of a normal subject as seen during PET scanning. The top panel shows a parametric flow image obtained using $\left[{ }^{15} \mathrm{O}\right] \mathrm{H}_{2} \mathrm{O}$ and $\mathrm{PET}$, and the bottom panel glucose uptake measured with $\left[{ }^{18} \mathrm{~F}\right] \mathrm{FDG}$ and PET under euglycaemic hyperinsulinaemic conditions. The bradykinin-infused leg $(\mathrm{BK})$ is shown on the right and the control leg (Cont) is shown on the left

\section{Mechanism of the insulin's effects on blood flow in skeletal muscle}

Effects of insulin on NO synthesis and Na/K ATPase activity. Independent observations by Scherrer et al. [15] and Steinberg et al. [28] showed that the insulininduced increase in blood flow could be abolished by inhibiting NO synthesis-dependent vasodilatation using L-N-monomethylarginine (L-NMMA) but not by other vasoconstrictors such as norepinephrine [15]. These in vivo observations are supported by recent studies performed in isolated skeletal muscle arterioles [29] and vascular endothelial cells [30]. In firstorder arterioles isolated from rat cremaster muscle, insulin-induced vasodilatation can be completely abolished by removal of the endothelium and by $\mathrm{N}^{\mathrm{G}}$. nitro-L-arginine (L-NNA, another inhibitor of ecNOS) but not by indomethacin [29]. Insulin also increases NO production in cultured human umbilical vein endothelial cells [30]. Inhibition of ecNOS, and inhibition of tyrosine kinases by genestein, both block insulin-induced NO release totally while wortmannin, an inhibitor of phosphatidylinositol 3-kinase, partly, blocks NO-release, suggesting that insulinstimulated NO release and glucose transport share common signalling elements in endothelial cells.

Another substance capable of blocking insulin-induced vasodilation in vivo is ouabain, a specific inhibitor of $\mathrm{Na}^{+} \mathrm{K}^{+}$-ATPase [16]. After ouabain pretreatment, L-NMMA has no effect on insulin-stimulated blood flow in human forearm vessels, suggesting that activation of endothelial cell $\mathrm{Na}^{+} \mathrm{K}^{+}$-ATPase and NO synthase are both essential steps in the signal transduction pathway ultimately leading to relaxation of vascular smooth muscle cells. Exactly how these steps are coupled is uncertain at present. One possibility is that the hyperpolarization, which follows insulin stimulation of $\mathrm{Na}^{+} \mathrm{K}^{+}$ATPase [31, 32], decreases intracellular $\mathrm{Ca}^{++}$concentrations in vascular smooth muscle cells leading to vasorelaxation [33]. On the other hand, hyperpolarization of the endothelial cells increases intracellular $\mathrm{Ca}^{++}$concentrations, which stimulates endothelial synthesis and release of NO [34, 35]. Interestingly, in hamster cremaster muscle, adenosine receptor antagonism and blockade of ATP-sensitive potassium channels prevent insulin-induced vasodilatation [36]. The significance of these observations for insulin regulation of blood flow in humans is, however, unclear as inhibition of NO synthesis has no effect on insulin-induced vasodilatation in this preparation [36].

Since local intra-arterial infusions of insulin also appear to increase blood flow (Fig. 3), the vasodilatory effect of insulin seems local rather than systemic. On the other hand, Scherrer et al. [37] showed that the flow response to insulin could also be blocked by treating normal subjects for $48 \mathrm{~h}$ with dexamethasone [37]. Given that it is difficult to exclude non-specific increases in blood flow, when catheters are inserted into the artery for local insulin administration, it remains somewhat uncertain whether insulin stimulates flow via a local or a central mechanism. However, the ability of insulin to stimulate flow seems specific to insulin and not mediated by an increase in glucose metabolism such as that induced by hyperglycaemia or fructose [38]. Infusion of a fat emulsion decreases glucose oxidation but has no effect on insulin's vasodilatory effect [39]. Normalization of glucose flux by glucose mass-action in insulin-resistant patients with IDDM also has no effect on insulin-stimulated blood flow [40].

Effects of insulin on the activity of the sympathetic nervous system. Under normoglycaemic conditions, physiological concentrations of insulin increase the activity of the sympathetic nervous system, as judged from increases in plasma norepinephrine [14, 41-44] but not epinephrine $[14,41]$ concentrations. Circulating norepinephrine under such conditions does not originate from the adrenal medulla but represents spillover from sympathetic nerve terminals [42, 45]. Physiological insulin concentrations, lower than those needed for vasodilation [46], also markedly increase in muscle sympathetic nerve activity, as measured directly using microneurography recording of multifibre sympathetic postganglionic nerve activity in the peroneal nerve $[14,38]$. The increases in muscle sympathetic nerve activity and plasma norepinephrine concentrations would be expected to induce vasoconstriction, via stimulation of $\alpha$-adrenergic receptors in blood vessels, rather than vasodilation. 
The latter possibility is supported by the occurrence of exaggerated vasodilatation after subcutaneous insulin in IDDM patients with autonomic neuropathy [47]. These data suggest that insulin has dual effects on blood flow, a vasodilatory effect mediated via NO-release, which becomes the dominating component at supraphysiological insulin concentrations, and a vasoconstrictive effect mediated via activation of the sympathetic nervous system at low physiological concentrations of insulin. Alterations in either sympathetic nervous system function or endothelium-dependent vasodilatation can therefore be predicted to modulate blood flow responses to insulin.

\section{Defects or lack thereof, of insulin-induced vasodilatation in insulin-resistant conditions}

Obesity. Rabinowitz and Zierler [3] were the first to examine the integrity of blood flow responses to insulin in obese subjects. In this study, the dose of insulin and duration of the intraarterial insulin infusion were physiological. Both basal and insulin-stimulated rates of forearm blood flow, measured using the indicator dilution technique, were comparable between obese and non-obese subjects [3]. However, it was in obese subjects in whom defective insulin-induced vasodilation was first observed and suggested to contribute to insulin resistance [8]. Laakso et al. [8] studied six obese and six normal men using stepwise sequential insulin infusions at rates varying between 10 and $1200 \mathrm{mU} / \mathrm{m}^{2} \cdot \min (0.25-30 \mathrm{mU} / \mathrm{kg} \cdot \mathrm{min})$. The total duration of the insulin infusions exceeded $6 \mathrm{~h}$. Both glucose extraction and insulin stimulation of blood flow were reduced in the obese compared to the non-obese subjects. Although the flow defect was observed at a physiological insulin concentration, this interpretation is confounded by the use of sequential insulin infusions to create the dose-response curve for insulin stimulation of blood flow [8]. Thus, insulin had been infused for $3 \mathrm{~h}$ before blood flow was measured. Since then, however, a blunted blood flow response to insulin has been found under more physiological conditions (insulin infusion $1 \mathrm{mU} /$ $\mathrm{kg} \cdot \min$ for $2 \mathrm{~h}$ ) in obese subjects [44]. Importantly, in the latter study, the flow defect in obese subjects was not explained by exaggerated muscle sympathetic nerve discharge response to insulin [44]. Of note, in both of the above studies total flow rather than muscle flow was quantitated. Since limbs of obese subjects contain more fat than those of lean subjects, the flow defect may have been overestimated. In keeping with this, direct measurement of blood flow in skeletal muscle of obese individuals using a physiological insulin dose $(1 \mathrm{mU} / \mathrm{kg} \cdot \mathrm{min}$ for $1.5 \mathrm{~h})$ did not reveal a defect in insulin-stimulated blood flow. This does not exclude the presence of a defect in skeletal muscle vasodilatation at higher insulin concentra- tions. If so, as suggested by flow measurements in the entire leg [8], this defect could reflect endothelial dysfunction since defects in vasodilatory responses to endothelium-dependent vasoactive agents have been found both across leg tissues [48] and in femoral muscle (Laine et al, unpublished data) in obese subjects. The flow defect does not, however, explain cellular insulin resistance since obese subjects have markedly diminished rates of glucose uptake, despite having increased interstitial insulin concentrations under steady-state normoglycaemic hyperinsulinaemic conditions [49].

Hypertension. Ferrannini et al. [50] was the first to convincingly demonstrate, in non-obese, young patients, that essential hypertension is associated with impaired insulin-mediated glucose uptake. This observation has been confirmed by several investigators both in patients with established [51-53] and borderline [54] hypertension, and in subjects prone to develop hypertension [55]. The insulin resistance is localized to peripheral tissues $[5,45,51,56]$. The contribution of defects in insulin-stimulated blood flow vs glucose extraction to reduced glucose uptake in hypertension has been examined in a total of seven studies $[5,45,51,56-59]$. With the exception of a subgroup of hypertensive patients characterized by high rates of erythrocyte $\mathrm{Na}^{+} \mathrm{Li}^{+}$countertransport [56], both basal and insulin-stimulated blood flows have been uniformly normal $[5,45,51,57-59]$ in patients with essential hypertension. These data are seemingly contradictory to those reported by Baron et al. [9], who found an inverse correlation between mean arterial blood pressure and leg blood flow using a pharmacological insulin infusion rate of $15 \mathrm{mU} / \mathrm{kg} \cdot \mathrm{min}$ in normotensive subjects. Whether this defect can be attributed to one or several of the abnormalities found in patients with essential hypertension such as excessive sympathetic activation [60], capillary rarefaction [61] or impaired endothelium-dependent vasodilatation $[58,62,63]$, is currently unclear. Of interest in this respect is the study of Taddei et al. [58] who measured both insulin-stimulated glucose uptake and endothelial function in patients with essential hypertension. Insulin resistance characterized the hypertensive patients and could be attributed to a defect in glucose extraction. In addition, the hypertensive patients also had a defect in endothelial function, as judged from the blood flow response to ACh [58]. A similar lack of a relationship between insulin-mediated glucose uptake and endothelial function was recently also reported by Natali et al. [64]. These data imply that insulin resistance of glucose uptake in essential hypertension is caused by a glucose extraction defect distinct from that responsible for impaired endothelium-dependent vasodilatation. This interpretation is in keeping with in vitro evidence showing that in skeletal muscle glucose transport is not coupled to 
active $\mathrm{Na}^{+} \mathrm{K}^{+}$transport [65] or insulin-induced hyperpolarization [66].

$I D D M$. In a total of 50 patients with IDDM and 40 normal subjects, in which we $[6,40,67]$ and others [68] have quantitated insulin-stimulated glucose uptake across a limb, insulin resistance has been localized to a defect in glucose extraction rather than blood flow. Furthermore, chronic hyperglycaemia, which is a major cause of insulin resistance in these patients (see [69] for review), causes insulin resistance by inducing a defect in glucose extraction rather than blood flow [70]. These studies were all performed using physiological concentrations of insulin. In contrast to these data, Baron et al. [10], studied five patients with IDDM and seven normal subjects, and found no difference in glucose extraction but a significant defect in insulin-stimulated blood flow between IDDM patients and normal subjects, at a supraphysiological insulin concentration [10]. The reason for this contradictory finding is unclear but again, as in the obese and the hypertensive subjects, could be explained by the experimental conditions, and by the patient characteristics. Defects in endotheliumdependent vasodilatation have been found in patients with IDDM, and this impairment has been related to the degree of glycaemic control [67]. The patients studied by Baron et al. [10] were poorly controlled $\left(\mathrm{HbA}_{\mathrm{I}} 14 \%\right.$, normal range 4-8\%) and were studied using a supraphysiological long-lasting insulin infusion, i.e. under conditions where defects in blood flow rather than those in glucose extraction are likely to be detected (Fig. 1).

NIDDM. As in patients with IDDM, studies in which insulin stimulation of glucose extraction and blood flow have been measured under physiological insulin concentrations using either venous occlusion plethysmography [71, 72], impedance plethysmography [73], indicator dilution $[7,74,75]$ or PET and $\left[{ }^{15} \mathrm{O}\right] \mathrm{H}_{2} \mathrm{O}$ [76] across leg [7, 72, 73, 76] and forearm [71, 74, 75] tissues have localized insulin resistance to glucose extraction. Even in studies in which limb blood flow has increased moderately in response to insulin infusion, no differences in blood flow responses to insulin have been found between normal subjects and patients with NIDDM $[12,77,78]$. Dela et al. [12, 77] infused insulin in a sequential step-wise sequential manner at rates $0.7,2.2$ and $12 \mathrm{mU} / \mathrm{kg} \cdot \min$ for $2 \mathrm{~h}$ each, while plasma glucose concentration was kept at its fasting value. Under these conditions, leg blood flow increased similarly in both normal subjects and obese patients with NIDDM [12, 77]. Tack et al. [78] measured forearm blood flow using venous occlusion plethysmography during a 90 min euglycaemic hyperinsulinaemic clamp study (insulin infusion $1.5 \mathrm{mU} /$ $\mathrm{kg} \cdot \mathrm{min}$ ), and found $30-40 \%$ increases in flow in both NIDDM patients and in normal subjects, but no differences between the groups. Results from these 10 negative studies contrast the findings of Laakso et al. [79], who studied six obese poorly controlled NIDDM patients using sequential insulin infusions at rates varying between 3 to $30 \mathrm{mU} / \mathrm{kg}$. min, and lasting a total of 7-9 $\mathrm{h}$ [79]. At the highest insulin concentrations employed, leg blood flow was lower in the patients with NIDDM than in their matched control subjects, suggesting that the flow defect was due to the diabetic state per se [79]. At least three factors could explain this contradictory finding. First, and as has been the case in all other insulin resistant conditions reviewed above, use of much longer $(6.5 \mathrm{~h})$ insulin infusions or higher doses of insulin (sequential infusions of $3,7.5,15$ and $30 \mathrm{mU} / \mathrm{kg} \cdot \mathrm{min}$ ) by Laakso et al. [79] compared to the 10 other studies [7, 12, 71-78] may have been responsible. Second, the NIDDM patients studied by Laakso et al. [79] were more obese (BMI $\left.33 \mathrm{~kg} / \mathrm{m}^{2}\right)$ than the obese non-diabetic control subjects $\left(30 \mathrm{~kg} / \mathrm{m}^{2}\right)$, and more obese than the patients studied by Dela et al. (BMI $29 \mathrm{~kg}$ / $\left.\mathrm{m}^{2}\right)[12,77]$ and Tack et al. (BMI $24 \mathrm{~kg} / \mathrm{m}^{2}$ ) [78]. Third, the patients studied by Laakso et al. [12, 77, 78] also had worse glycaemic control than those in the other studies using higher insulin doses.

\section{Effects or lack thereof, of changes in blood flow on insulin-stimulated glucose uptake}

One approach to establish whether blood flow is a regulator of insulin action is to change blood flow by some intervention and then determine whether glucose uptake changes. These studies are complicated by at least two factors. First, the agent which is used to stimulate blood flow should not have flow-independent effects on glucose uptake. Second, the drug should ideally be administered intra-arterially rather than systemically to avoid secondary effects on glucose uptake such as those resulting from changes in systemic haemodynamics and accompanying counterregulatory responses. Third, the drug should not increase oxygen consumption, i. e. both glucose and oxygen consumption should be measured in these studies. The reasoning underlying the last requirement is that alteration in insulin sensitivity involves merely a shift in fuel preference, i.e. an insulin-resistant person utilizes roughly the same amount of oxygen as an insulin-insensitive person but the fuel mixture used for energy production contains more fat than carbohydrate. It is obvious from the studies reviewed below and summarized in Table 1 that no study has fulfilled all these requirements.

Natali et al. [80] measured both oxygen consumption and glucose uptake in patients with mild essential hypertension during infusion of insulin/glucose alone or in combination with adenosine (Table 1 ). Adenosine doubled blood flow but had no effect on 
Table 1. Summary of interventions studies testing the hypothesis that glucose uptake can be modified by altering blood flow in humans

\begin{tabular}{|c|c|c|c|c|c|}
\hline Vasoactive agent & Local vs systemic & $\begin{array}{l}\% \text { change in blood } \\
\text { flow }^{\mathrm{a}}\end{array}$ & $\begin{array}{l}\% \text { change in glucose } \\
\text { uptake }^{\mathrm{a}}\end{array}$ & $\begin{array}{l}\text { Serum insulin } \\
(\mathrm{mU} / \mathrm{l})\end{array}$ & First author [ref.] \\
\hline Adenosine & Local & 100 & NS & 62 & Natali [80] \\
\hline Bradykinin & Local & 58 & NS & 78 & Nuutila [82] \\
\hline Angiotensin II & Local & -38 & NS & 100 & Jamerson [83] \\
\hline Methacholine & Local & $\begin{array}{r}79 \\
224\end{array}$ & $\begin{array}{r}47 \\
116\end{array}$ & $\begin{array}{r}950 \\
23\end{array}$ & Baron [107] \\
\hline L-NMMA & Local & $\begin{array}{l}-48 \\
-51\end{array}$ & $\begin{array}{l}-23 \\
-28\end{array}$ & $\begin{array}{r}81 \\
224\end{array}$ & Baron [86] \\
\hline
\end{tabular}

${ }^{a}$ All changes not denoted NS were statistically significant compared to the appropriate control study

glucose uptake. The ratio of glucose to oxygen uptake was also not altered by adenosine. Similarly, a significant increase in blood flow with an intrafemoral artery infusion of bradykinin, which does not have any effect on glucose uptake in isolated myocytes [81], does not change glucose uptake in either normal [82] or obese (Laine et al. unpublished data) subjects (Fig.5). Intraarterial infusion of angiotensin II decreases blood flow and increases glucose extraction but does not change glucose uptake [83]. The latter result contrasts those observed during systemic angiotensin II infusions, where glucose uptake was found to increase in all three studies where flow was also measured $[18,84,85]$. Two of these studies were not controlled with respect to time $[18,85]$, and in the study of Buchanan et al. [18], the insulin concentration was significantly higher during angiotensin and insulin infusions compared to insulin alone, due to a decrease in renal blood flow and insulin clearance. Regardless, the increase in glucose uptake was associated with an increase in blood flow in two of the studies $[18,84]$ and with a decrease in one [85]. In contrast to the lack of effect of vasodilatation with adenosine [80] and bradykinin [82], Baron et al. [86] has reported that a decrease in blood flow by an intrafemoral artery infusion of L-NMMA decreases glucose uptake, and that an increase in blood flow by a local infusion of methacholine increases leg glucose uptake. These data are confounded by the ability of L-NMMA to decrease glucose uptake in isolated extensor digitorum longus muscle [87]. There are, to our knowledge, no data available regarding effects of methacholine on glucose uptake in vitro. Taken together the data available support the view that glucose uptake cannot be altered by changing blood flow when agents which do not themselves have effects on glucose uptake in muscle cells are used to modulate blood flow.

Nutritive compared to non-nutritive flow. Studies performed in the constant flow rat hindlimb preparation have suggested that vasoactive agents may increase or decrease metabolism depending on their site of ac- tion [88]. Clark et al. [88] have proposed to classify vasoconstrictors into Type $A$ and Type $B$ agents. Type A agents include agents such as angiotensins which increase oxygen uptake, while type B agents decrease oxygen uptake [88]. Insulin was recently found to increase the metabolism of 1-methylxanthine, an exogenously added substrate for xanthine oxidase and an indicator of capillary recruitment [89]. In the latter study, a pharmacological insulin dose $(10 \mathrm{mU} / \mathrm{kg} \cdot \mathrm{min})$ was infused for $2 \mathrm{~h}$ in the rat. Blood flow increased, as measured by ultrasound probes, by $80 \%$ [89]. This would imply that insulin, at least at high doses, increases capillary recruitment and oxygen consumption. The latter was not, however, measured [89]. The observation that high doses of insulin increase blood volume in human skeletal muscle is consistent with the idea that capillary recruitment occurs [90]. Thus, not only total flow but also flow distribution should be quantitated in studies addressing effects of a vasoactive agent on insulin action. There are, at least at present no methods suitable for human use to measure distribution of blood flow in nutritive compared to non-nutritive vessels. Analysis of flow heterogeneity using analysis of relative and absolute dispersion of flow within human skeletal muscle using PET and $\left[{ }^{15} \mathrm{H}_{2} \mathrm{O}\right]$ does not address this question but provides a tool to quantitate flow in $9 \mathrm{~mm}^{2}$ areas in insulin-sensitive and resistant individuals [91]. Such analysis revealed that insulin increases absolute but not relative dispersion of flow in human skeletal muscle and that flow distribution is unaltered in patients with NIDDM [76].

\section{Beyond glucose uptake: insulin's vascular effects and cardiovascular disease}

From the above it is obvious that defects in insulin-induced vasodilatation do not explain or contribute to insulin resistance of glucose uptake under physiological conditions. However, defects in insulin-stimulated blood flow can be detected under extreme conditions, i. e. under very long-lasting and high dose insulin infu- 
sions, in both obese and hypertensive subjects and in patients with IDDM and NIDDM. Since insulin vasodilates via an endothelium-dependent mechanism, the latter data might be of some relevance for the understanding of the association between insulin resistance and vascular disease.

Insulin and endothelium-dependent vasodilatation. In familial or essential hypercholesterolaemia, the blood flow response to endothelium-dependent vasoactive agents such as acetylcholine, but not to endothelium-independent agents such as sodium nitroprusside has repeatedly been found to be impaired in direct proportion to the increase in serum LDL cholesterol concentration [92-97]. This contrasts data showing unaltered insulin stimulated glucose uptake in these patients [98-100] and is consistent with the contention that endothelium-dependent vasodilatation and insulin sensitivity of glucose uptake are distinct phenomena. In other conditions, such as obesity [48], hypertension [62, 63], IDDM [67, 101] and NIDDM (see [102] for review), endothelial dysfunction and insulin resistance frequently coexist. Since the ability of pharmacological doses of insulin to vasodilate is also impaired in all these conditions (vide supra), at least two possibilities arise. First, endothelial dysfunction caused by whatever mechanism (chronic hyperglycaemia and associated modifications in plasma lipids and lipoproteins [67, 102], obesity [48], hypertension [62, 63]), also impairs the ability of insulin to vasodilate in an endothelium-dependent fashion. According to this interpretation, once NO synthesis or destruction is altered by one factor, this will impede upon the ability of all other NO-dependent vasodilatators to act properly. For example, in obese subjects, both insulin-induced potentiation of endothelium-dependent vasodilatation to methacholine and methacholine-induced vasodilatation are impaired [67]. Second, endothelium-dependent vasodilatation could be impaired secondary to altered insulin action in blood vessels but there are no data to directly support this possibility at present.

Other vascular effects of insulin. Endogenous hyperinsulinaemia, a marker of insulin resistance, or some or many of the consequences of insulin resistance, is associated with increased atherosclerosis [103-105]. Among several potential candidates, hyperinsulinaemia itself still is one. Interestingly, recent advances in the understanding of insulin signalling events have enabled study of insulin signalling events directly in vascular stroma [106]. Preliminary data showed blunted stimulation of insulin receptor substrate (IRS-2) associated phosphoinositol (PI3)-kinase activity, but normal stimulation of mitogen activated protein (MAP) kinase (P42/44) tyrosine phosphorylation in aorta and mesenteric blood vessels in obese as compared to lean Zucker (fa/fa) rats [106]. As mentioned above, activation of PI3-kinase by insulin appears coupled with production of NO in human endothelial cells [30]. These data raise the intriguing possibility that atherogenic actions of insulin, such as stimulation of vascular growth via the MAP kinase pathway, may not become insulin-resistant and will therefore be excessively activated in insulin-resistant animals, while anti-atherogenic actions, such as production of NO in endothelial cells, may be blunted.

\section{Conclusions}

To conclude, insulin, at physiological concentrations, which stimulate glucose extraction over 10-fold, has trivial if any effects on blood flow. However, prolonged infusions of insulin increase flow continuously. A doubling of flow with a high physiological insulin concentration takes approximately 4 to $6 \mathrm{~h}[8$, 19]. The magnitude of this increase is dependent on individual factors such as limb muscularity and physical fitness rather than the technique or site of blood flow measurement. This physiological knowledge combined with lack of finding of flow defects in all common insulin-resistant states under physiological conditions, and negative results in intervention studies where the vasoactive agent has no flow-independent effects on glucose uptake, implies that insulininduced vasodilatation is a pharmacologic phenomenon from the point of view of glucose uptake. On the other hand, the interaction of insulin with blood vessels at various levels such as production of NO and stimulation of vascular smooth muscle cell growth is an exciting and potentially important new avenue of research worth pursuing - after all, from a clinical point of view, NIDDM is a disease of blood vessels, not muscle.

Acknowledgements. I want to thank other members of my research colleagues who made important contributions to the studies reviewed above, including Drs. Sari Mäkimattila, Antti Virkamäki, Raija Malmström, John Cockcroft, Per-Henrik Groop, Matti Mäntysaari and Paula Summanen, and the superb technicians Sari Hämäläinen and Kati Tuomola. I am also indebted to the Turku PET Center, particularly Drs. Pirjo Nuutila, Juhani Knuuti, Marja Raitakari and Hanna Laine for pleasant and fruitful collaboration. Supported by grants from the American Diabetes Association (H.Y.), the Academy of Finland (H.Y.), the Novo Nordisk Foundation (H.Y.), the Helsinki University M.D./Ph.D. program (T.U.), and the Sigrid Juselius Foundation (H. Y.).

\section{References}

1. Andres R, Cader G, Zierler KL (1956) The quantitatively minor role of carbohydrate in oxidative metabolism by skeletal muscle in intact man in the basal state. Measurements of oxygen and glucose uptake and carbon dioxide and lactate production in the forearm. J Clin Invest 35: 671-682 
2. Zierler KL (1961) Theory of the use of arteriovenous concentration differences for measuring metabolism in steady-state and non-steady-states. J Clin Invest 40: 2111-2125

3. Rabinowitz D, Zierler KL (1962) Forearm metabolism in obesity and its response to intra-arterial insulin. Characterization of insulin resistance and evidence for adaptive hyperinsulinism. J Clin Invest 41: 2173-2181

4. Andres R, Baltzan MA, Cader G, Zierler KL (1962) Effect of insulin on carbohydrate metabolism and on potassium in the forearm of man. J Clin Invest 41: 108-115

5. Natali A, Santoro D, Palombo C, Cerri M, Ghione M, Ferrannini E (1991) Impaired insulin action on skeletal muscle metabolism in essential hypertension. Hypertension 17: $170-178$

6. Yki-Järvinen H, Sahlin K, Ren JM, Koivisto VA (1990) Localization of the rate-limiting defect for glucose disposal in skeletal muscle of insulin-resistant type 1 diabetic patients. Diabetes 39: 157-167

7. DeFronzo RA, Gunnarson R, Björkman O, Olsson M, Wahren J (1985) Effects of insulin on peripheral and splanchnic glucose metabolism in noninsulin-dependent (type II) diabetes mellitus. J Clin Invest 76: 149-155

8. Laakso M, Edelman SV, Brechtel G, Baron AD (1990) Decreased effect of insulin to stimulate skeletal muscle blood flow in obese man. J Clin Invest 85: 1844-1882

9. Baron AD, Brechtel-Hook G, Johnson A, Hardin D (1993) Skeletal muscle blood flow. A possible link between insulin resistance and blood pressure. Hypertension 21: 129-135

10. Baron AD, Laakso M, Brechtel G, Edelman SV (1991) Mechanism of insulin resistance in insulin-dependent diabetes mellitus: a major role for reduced skeletal muscle blood flow. J Clin Endocrinol Metab 73: 637-643

11. Laakso M, Edelman SV, Brechtel G, Baron AD (1992) Impaired insulin-mediated skeletal muscle blood flow in patients with NIDDM. Diabetes 41: 1076-1083

12. Dela F, Larsen JJ, Mikines KJ, Galbo H (1995) Normal effect of insulin to stimulate leg blood flow in NIDDM. Diabetes 44: 221-226

13. Bonadonna RC, Saccomani MP, Seely L et al. (1993) Glucose transport in human skeletal muscle. The in vivo response to insulin. Diabetes 42: 181-198

14. Anderson EA, Hoffmann RP, Balon TW, Sinkey CA, Mark AL (1991) Hyperinsulinemia produces both sympathetic neural activation and vasodilatation in normal humans. J Clin Invest 87: 2246-2252

15. Scherrer U, Randin D, Vollenweider P, Vollenweider L, Nicod P (1994) Nitric oxide release accounts for insulin's vascular effects in humans. J Clin Invest 94: 2511-2515

16. Tack CJ, Lutterman JA, Vervoot G, Thien T, Smits P (1996) Activation of the sodium-potassium pump contributes to insulin-induced vasodilatation in humans. Hypertension 28: 426-432

17. Raitakari M, Nuutila P, Ruotsalainen U et al. (1996) Evidence for dissociation of insulin stimulation of blood flow and glucose uptake in human skeletal muscle. Studies using $\left[{ }^{15} \mathrm{O}\right] \mathrm{H}_{2} \mathrm{O},\left[{ }^{18} \mathrm{~F}\right] \mathrm{FDG}$ and positron emission tomography. Diabetes 45: 1471-1477

18. Buchanan TA, Thawani H, Kades W et al. (1993) Angiotensin II increases glucose utilization during acute hyperinsulinemia via a hemodynamic mechanism. J Clin Invest 92: 720-726

19. Utriainen T, Malmström R, Mäkimattila S, Yki-Järvinen H (1995) Methodological aspects, dose-response characteristics and causes of interindividual variation in insulin stimulation of limb blood flow in normal subjects. Diabetologia 38: 555-564

20. Yki-Järvinen H, Young AA, Lamkin C, Foley JE (1987) Kinetics of glucose disposal in whole body and across the forearm in man. J Clin Invest 79: 1713-1719

21. Elder GCB, Bradbury K, Roberts R (1982) Variability of fiber type distributions within human muscles. J Appl Physiol 53: 1473-1480

22. Johnson MA, Polgar J, Weightman D, Appleton D (1973) Data on the distribution of fibre types in thirty-six human muscles. J Neurol Sci 18: 111-129

23. Nuutila P, Knuuti MJ, Heinonen OJ et al. (1994) Different alterations in the insulin-stimulated glucose uptake in the athlete's heart and skeletal muscle. J Clin Invest 93: 2267-2274

24. Raitakari M, Nuutila P, Ruotsalainen U et al. (1996) The relationship between limb and muscle blood flow in man. J Physiol 469: 543-549

25. Utriainen T, Mäkimattila S, Virkamäki A, Lindholm H, Sovijärvi A, Yki-Järvinen H (1996) Physical fitness and endothelial function (nitric oxide synthesis) are independent determinants of insulin-stimulated blood flow in normal subjects. $J$ Clin Endocrinol Metab 81: 4258-4263

26. Utriainen T, Holmäng A, Björntorp P et al. (1996) Physical fitness, muscle morphology, and insulin-stimulated limb blood flow in normal subjects. Am J Physiol 270:E905-E911

27. Lindbom L (1983) Microvascular blood flow distribution in skeletal muscle. An intravital microscopic study in the rabbit. Acta Physiol Scand [Suppl] 525: 1-40

28. Steinberg HO, Brechtel G, Johnson A, Fireberg N, Baron AD (1994) Insulin-mediated skeletal muscle vasodilatation is nitric oxide dependent. A novel action of insulin to increase nitric oxide release. J Clin Invest 94: 1172-1179

29. Chen Y-Y, Messina EJ (1996) Dilatation of isolated skeletal muscle arterioles by insulin is endothelium-dependent and nitric oxide mediated. Am J Physiol 270:H2120-H2124

30. Zeng G, Quon MJ (1996) Insulin-stimulated production of nitric oxide is inhibited by Wortmannin. Direct measurement in vascular endothelial cells. J Clin Invest 98: 894-898

31. DeFronzo RA, Beckles AD (1979) Glucose metabolism following chronic metabolic acidosis in man. Am J Physiol 236:E328-E334

32. Ewart HS, Klip A (1995) Hormonal regulation of the $\mathrm{Na}^{+}$$\mathrm{K}^{+}$-ATPase: mechanisms underlying rapid and sustained changes in pump activity: Am J Physiol 269:C295-C311

33. Kahn AM, Seidel CL, Allen JC, O’Neil RG, Shelat H, Song T (1993) Insulin reduces contraction and intracellular calcium concentration in vascular smooth muscle. Hypertension 22: 735-742

34. Busse R, Mülsch A, Fleming I, Hecker M (1993) Mechanisms of nitric oxide release from the vascular endothelium. Circulation 87:V-18-V-25

35. Dinerman JL, Lowenstein CJ, Synder SH (1993) Molecular mechanisms of nitric oxide regulation. Potential relevance to cardiovascular disease. Circ Res 73: 217-222

36. McKay MK, Hester RL (1996) Role of nitric oxide, adenosine, and ATP-sensitive potassium channels in insulininduced vasodilatation. Hypertension 28: 202-208

37. Scherrer U, Vollenweider P, Randin D, Jéquier E, Nicod P, Tappy L (1993) Suppression of insulin-induced sympathetic activation and vasodilation by dexamethasone in humans. Circulation 88: 388-394

38. Vollenweider P, Tappy L, Randin D et al. (1993) Differential effects of hyperinsulinemia and carbohydrate metabo- 
lism on sympathetic nerve activity and muscle blood flow in humans. J Clin Invest 92: 147-154

39. Vollenweider L, Tappy L, Owlya R, Jéquier E, Nicod P, Scherrer U (1995) Insulin-induced sympathetic activation and vasodilatation in skeletal muscle. Effects of insulin resistance in lean subjects. Diabetes 44: 641-645

40. Mäkimattila S, Virkamäki A, Malmström R, Utriainen T, Yki-Järvinen H (1996) Insulin resistance in type I diabetes mellitus: A major role for reduced glucose extraction. J Clin Endocrinol Metab 81: 707-712

41. Randin D, Vollenweider P, Tappy L, Jéquier E, Nicod P, Scherrer U (1994) Effects of adrenergic and cholinergic blockade on insulin-induced stimulation of calf blood flow in humans. Am J Physiol 266:R809-R816

42. Lembo G, Capaldo B, Rendina V et al. (1994) Acute noradrenergic activation induces insulin resistance in human skeletal muscle. Am J Physiol 266:E242-E247

43. Berne C, Fagius J, Pollare T, Hjemdahl P (1992) The sympathetic response to euglycaemic hyperinsulinaemia. Diabetologia 35: 873-879

44. Vollenweider P, Randin D, Tappy L, Jéquier E, Nicod P, Scherrer U (1994) Impaired insulin-induced sympathetic neural activation and vasodilatation in skeletal muscle in obese humans. J Clin Invest 93: 2365-2371

45. Lembo G, Napoli R, Capaldo B et al. (1992) Abnormal sympathetic overactivity evoked by insulin in the skeletal muscle of patients with essential hypertension. J Clin Invest 90: 24-29

46. Hausberg M, Mark AL, Hoffman RP, Sinkey CA, Anderson EA (1995) Dissociation of sympathoexcitatory and vasodilator actions of modestly elevated plasma insulin levels. J Hypertension 13: 1015-1021

47. Porcellati F, Fanelli C, Bottini P et al. (1993) Mechanisms of arterial hypotension after therapeutic dose of subcutaneous insulin in diabetic autonomic neuropathy. Diabetes 42: $1055-1064$

48. Steinberg HO, Chaker H, Leaming R, Johnson A, Brechtel G, Baron AD (1996) Obesity/insulin resistance is associated with endothelial dysfunction. Implications for the syndrome of insulin resistance. J Clin Invest 97: 2601-2610

49. Castillo C, Bogardus C, Bergman R, Thuillez P, Lillioja S (1994) Interstitial insulin concentrations determine glucose uptake rates but not insulin resistance in lean and obese men. J Clin Invest 93: 10-16

50. Ferrannini E, Buzzigoli G, Bonadonna R et al. (1987) Insulin resistance in essential hypertension. N Engl J Med 317: $350-357$

51. Capaldo B, Lembo G, Napoli R et al. (1991) Skeletal muscle is a primary site of insulin resistance in essential hypertension. Metabolism 40: 1320-1322

52. Dengel DR, Pratley RE, Hagberg JM, Golberg AP (1994) Impaired insulin sensitivity and maximal responsiveness in older hypertensive men. Hypertension 23: 320-324

53. Pollare T, Lithell H, Berne C (1990) Insulin resistance is a characteristic feature of primary hypertension independent of obesity. Metabolism 40: 1320-1322

54. Falkner B, Hulman S, Kusher H (1993) Insulin-stimulated glucose utilization and borderline hypertension in young adult blacks. Hypertension 22: 18-25

55. Hulthen UL, Endre T, Mattiasson I, Berglund G (1995) Insulin and forearm vasodilatation in hypertension-prone men. Hypertension 25: 214-218

56. Doria A, Fioretto P, Avogaro A et al. (1991) Insulin resistance is associated with high sodium-lithium countertransport in essential hypertension. Am J Physiol 261: E684-E691
57. O'Shaughnessy IM, Myers TJ, Stepniakowski K et al. (1995) Glucose metabolism in abdominally obese hypertensive and normotensive subjects. Hypertension 26: 186-192

58. Taddei S, Virdis A, Mattei P, Natali A, Ferrannini E, Salvetti A (1995) Effect of insulin on acetylcholine-induced vasodilatation in normotensive subjects and patients with essential hypertension. Circulation 92: 2911-2918

59. Hunter SJ, Harper R, Ennis CN, Sheridan B, Atkinson AB, Bell PM (1997) Skeletal muscle blood flow is not a determinant of insulin resistance in essential hypertension. J Hypertens 15: 73-77

60. Anderson EA, Sinkey CA, Lawton WJ, Mark AL (1989) Elevated sympathetic nerve activity in borderline hypertensive humans. Evidence from direct intraneural recordings. Hypertension 14: 177-183

61. Henrich HA, Romen W, Heimgärtner W, Harting E, Bäumer F (1988) Capillary rarefaction characteristic of the skeletal muscle of hypertensive patients. Klin Wochenschr 66: 54-60

62. Kilcoyne CM, Quyyumi AA, Cannon RO (1995) Impaired endothelium-dependent vasodilatation in patients with essential hypertension. Circulation 91: 1732-1738

63. Panza JA, Quyyumi AA, Brush JEJ, Epstein SE (1990) Abnormal endothelium-dependent vascular relaxation in patients with essential hypertension. N Engl J Med 323: 22-27

64. Natali A, Taddei S, Galvan AQ et al. (1997) Insulin sensitivity, vascular reactivity, and clamp-induced vasodilatation in essential hypertension. Circulation 96: 849-855

65. ClausenT (1966) The relationship between the transport of glucose and cations across cell membranes in isolated tissues. II Effects of $\mathrm{K}^{+}$free medium, ouabain, and insulin upon the fate of glucose in rat diaphragm. Biochim Biophys Acta 120: 361-368

66. Clausen T, Flatman JA (1987) Effects of insulin and epinephrine on $\mathrm{Na}^{+} \mathrm{K}^{+}$and glucose transport in soleus muscle. Am J Physiol 252:E492-E499

67. Mäkimattila S, Virkamäki A, Groop P-H et al. (1996) Chronic hyperglycemia impairs endothelial function and insulin sensitivity via different mechanisms in insulin-dependent diabetes mellitus. Circulation 94: 1276-1282

68. Tessari P, Biolo G, Inchiostro S et al. (1990) Effects of insulin on whole body and forearm leucine and KIC metabolism in type 1 diabetes. Am J Physiol 259:E96-E103

69. Yki-Järvinen H (1992) Glucose toxicity. Endocr Rev 13: 415-431

70. Vuorinen-Markkola H, Koivisto VA, Yki-Järvinen $\mathrm{H}$ (1992) Mechanisms of hyperglycemia-induced insulin resistance in whole body and skeletal muscle of type 1 diabetic patients. Diabetes 41: 571-580

71. Bak JF, Moller N, Schmitz O, SaFk A, Pedersen O (1992) In vivo insulin action and muscle glycogen synthase activity in type 2 (non-insulin-dependent) diabetes mellitus: effects of diet treatment. Diabetologia 35: 777-784

72. Mandarino LJ, Consoli A, Jain A, Kelley DE (1996) Interaction of carbohydrate and fat fuels in human skeletal muscle: impact of obesity and NIDDM. Am J Physiol 270:E463-E470

73. Kelley DE, Mandarino LJ (1990) Hyperglycemia normalizes insulin-stimulated skeletal muscle glucose oxidation and storage in noninsulin-dependent diabetes mellitus. J Clin Invest 86: 1999-2007

74. Bonadonna RC, Del Prato S, Saccomani MP et al. (1993) Transmembrane glucose transport in skeletal muscle of patients with non-insulin-dependent diabetes. J Clin Invest 92: 486-494 
75. Bonadonna RC, Del Prato S, Bonora E et al. (1996) Roles of glucose transport and glucose phosphorylation in muscle insulin resistance of NIDDM. Diabetes 45: 915-925

76. Utriainen T, Nuutila P, Takala T et al. (1997) Intact insulin stimulation of skeletal muscle blood flow, its heterogeneity and redistribution but not of glucose uptake in non-insulin-dependent diabetes mellitus. J Clin Invest 100: 777-785

77. Dela F, Larsen JJ, Mikines KJ, Ploug T, Petersen LN, Galbo H (1995) Insulin-stimulated muscle glucose clearance in patients with NIDDM. Effects of one-legged physical training. Diabetes 44: 1010-1020

78. Tack CJJ, Smits P, Willemsen JJ, Lenders JWM, Thien T, Lutterman JA (1996) Effects of insulin on vascular tone and sympathetic nervous system in NIDDM. Diabetes 45: $15-22$

79. Baron AD, Laakso M, Brechtel G, Edelman SV (1991) Reduced capacity and affinity of skeletal muscle for insulin-mediated glucose uptake in non-insulin-dependent diabetes mellitus. J Clin Invest 87: 1186-1194

80. Natali A, Bonadonna R, Santoro D et al. (1994) Insulin resistance and vasodilatation in essential hypertension. Studies with adenosine. J Clin Invest 94: 1570-1576

81. Rosen P, Eckel J, Reinauer H (1983) Influence of bradykinin on glucose uptake and metabolism studied in isolated cardiac myocytes and isolated perfused rat hearts. Hoppe-Seyler's Z Physiol Chem 364: 1431-1438

82. Nuutila P, Raitakari M, Laine H et al. (1996) Role of blood flow in regulating insulin-stimulated glucose uptake in humans. Studies using bradykinin, $\left[{ }^{15} \mathrm{O}\right]$ water, and $\left[{ }^{18} \mathrm{~F}\right]$ fluoro-deoxy-glucose and positron emission tomography. J Clin Invest 97: 1741-1747

83. Jamerson JK, Nesbitt SD, Amerena JV, Grant E, Julius S (1996) Angiotensin mediates forearm glucose uptake by hemodynamic rather than direct effects. Hypertension 27: $854-858$

84. Fliser D, Arnold U, Kohl B, Hartung R, Ritz E (1993) Angiotensin II enhances insulin sensitivity in healthy volunteers under euglycemic conditions. J Hypertens 11: 983-988

85. Widgren BR, Urbanavicius V, Wikstrand J, Attvall S, Persson B (1993) Low-dose angiotensin II increases glucose disposal rate during euglycemic hyperinsulinemia. Am J Hypertens 6: 892-895

86. Baron AD, Steinberg HO, Chaker H, Leaming R, Johnson A, Brechtel G (1995) Insulin-mediated skeletal muscle vasodilatation contributes to both insulin sensitivity and responsiveness in lean humans. J Clin Invest 96: 786-792

87. Balon TW, Nadler JL (1994) Nitric oxide release is present from incubated skeletal muscle preparations. J Appl Physiol 77: 2519-2521

88. Clark MG, Colquhoun EQ, Rattigan S, Dora KA, Eldershaw TPD, Hall JL, Ye J (1995) Vascular and endocrine control of muscle metabolism. Am $\mathrm{J}$ Physiol 268:E797-E812

89. Rattigan S, Clark MG, Barrett EJ (1997) Hemodynamic actions of insulin in rat skeletal muscle. Evidence for capillary recruitment. Diabetes 46: 1381-1388

90. Raitakari M, Ruotsalainen U, Teräs M et al. (1995) Insulin increases blood volume in human skeletal muscle. Studies using $\left[{ }^{15} \mathrm{O}\right]$-labeled carbon monoxide and positron emission tomography. Am J Physiol 269:E1000-E1005

91. Vicini P, Bonadonna R, Utriainen T, Nuutila P, Yki-Järvinen H, Cobelli C (1997) Estimation of blood flow heterogeneity distribution in human skeletal muscle from posi- tron emission tomography data. Annals of Biomedical Engineering 25: 906-910

92. Anderson TJ, Meredith IT, Charbonneau F et al. (1996) Endothelium-dependent coronary vasomotion relates to the susceptibility of LDL to oxidation in humans. Circulation 93: 1647-1650

93. Heitzer T, Ylä-Herttuala S, Luoma J et al. (1996) Cigarette smoking potentiates endothelial dysfunction of forearm resistance vessels in patients with hypercholesterolemia. Circulation 93: 1346-1353

94. Casino PR, Kilcoyne CM, Quyyumi AA, Hoeg JM, Panza JA (1993) The role of nitric oxide in endothelium-dependent vasodilation of hypercholesterolemic patients. Circulation 88: 2541-2547

95. Gilligan DM, Sack MN, Guetta V et al. (1994) Effect of antioxidant vitamins on low density lipoprotein oxidation and impaired endothelium-dependent vasodilation in patients with hypercholesterolemia. J Am Coll Cardiol 24: 1611-1617

96. Craeger MA, Cooke JP, Mendelsohn ME et al. (1990) Impaired vasodilation of forearm resistance vessels in hypercholesterolemic humans. J Clin Invest 86: 228-234

97. Chowienczyk PJ, Watts GF, Cockroft JR, Ritter JM (1992) Impaired endothelium-dependent vasodilation of forearm resistance vessels in hypercholesterolaemia. Lancet 340: 1430-1432

98. Karhapää P, Voutilainen E, Kovanen P, Laakso M (1993) Insulin resistance in familial and nonfamilial hypercholesterolaemia. Atherosclerosis and Thrombosis 13: 41-47

99. Galvan AQ, Santoro D, Natali A et al. (1993) Insulin sensitivity in familial hypercholesterolemia. Metabolism 42: 1359-1364

100. Sheu WHH, Shieh SM, Fuh MMT et al. (1993) Insulin resistance, glucose intolerance and hyperinsulinemia. Hypertriglyceridemia versus hypercholesterolemia. Atherosclerosis and Thrombosis 13: 367-370

101. Elliot TG, Cockroft JR, Groop P-H, Viberti GC, Ritter JM (1993) Inhibition of nitric oxide synthesis in forearm vasculature of insulin dependent diabetic patients: blunted vasoconstriction in patients with microalbuminuria. Clin Sci 85: 687-693

102. Chowienczyk PJ, Watts GF (1997) Endothelial function, insulin resistance and non-insulin-dependent diabetes. Endocrinol Metab 4: 225-232

103. Pyörälä K (1979) Relationship of glucose tolerance and plasma insulin in the incidence of coronary heart disease. Results from two population studies in Finland. Diabetes Care 2: 131-141

104. Welborn TA, Wearne K (1979) Coronary heart disease incidence and cardiovascular mortality in Busselton with reference to glucose and insulin concentrations. Diabetes Care 2: 154-160

105. Ducimetiere P, Eschwege JL, Papoz JL et al. (1980) Relationship of plasma insulin levels to the incidence of myocardial infarction and coronary heart disease mortality in a middle-aged population. Diabetologia 19: 205-210

106. Jiang Z, Lin Y-W, Clermont A, Igarashi M, King G (1997) Direct demonstration of selective insulin resistance on PI3-kinase pathway in vascular tissues of obese Zucker (fa/fa) rats. Diabetes 46: 54A(Abstract)

107. Baron AD, Steinberg H, Brechtel G, Johnson A (1994) Skeletal muscle blood flow independently modulates insulin-mediated glucose uptake. Am J Physiol 266:E248-E253 